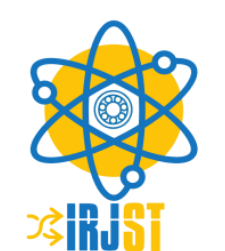

Available online at https://www.irjst.com/

International Research Journal of Science and Technology

ISSN: $2707-3955$

DOI: https://doi.org/10.46378/irjst.2020.010309

\title{
Assessing the Teaching Aptitude: A Longitudinal Study of Myanmar Teacher Trainees Yar Zar Chit
}

Lecturer, Department of Educational Psychology, Sagaing University of Education, Myanmar

\begin{tabular}{llll}
\multicolumn{2}{l}{ Paper Status } & & \\
\hline Received : & Apr 2020 \\
Accepted : & May 2020 \\
Published : & Jun 2020
\end{tabular}

Key Words

Aptitude

Longitudinal Study

Teaching Aptitude

Teacher Trainee

\begin{abstract}
This study investigated the teaching aptitude of BEd 2016 December intake teacher trainees during their attendance in Sagaing University of Education, Myanmar. A total of 263 teacher trainees in Sagaing University of Education participated in this study. Longitudinal research design and survey method were used. The instrument for this research was adapted from Teaching Aptitude of Indian Competitive Exams of Chhattisgarh (TAICE). The data were collected at four different times. Finally, to confirm the results, the interview protocols were done. According to the research findings, it was found that the teacher trainees' teaching aptitudes were significantly improved during three academic years. However, it was found that there was no significant main effect of gender. Similarly, there was also no significant main effect of previous achievement. This research hopes that the teacher trainers and the leaders of the teacher training programs will get some ideas to promote the teaching aptitude of the trainees.
\end{abstract}

Copyright (C) 2020: Yar Zar Chit. This is an open access distribution, and reproduction in any medium, provided Access article distributed under the Creative Commons Attribution License the original work is properly cited License, which permits unrestricted use.

Citation: Yar Zar Chit. “Assessing the Teaching Aptitude: A Longitudinal Study of Myanmar Teacher Trainees". International Research Journal of Science and Technology, 1 (3), 242-246, 2020.

\section{Introduction}

Today is the science and technology era. Sometimes, people also called as the age of competition. For facing many challenges in the competitive world, education plays a dynamic role. The quality of education that is provided to the children depends on the quality of the teachers. The quality of teachers in turn, definitely depends on the way in which they had received training. However, a teacher with innumerable degree and high profile personality cannot necessarily be termed as a good teacher. The performance of good teacher depends upon the specialization of the subject or fields to be taught and professional knowledge and understanding of educational process and teaching skills. It is very necessary on the part of the teacher to perform effectively in order to bring out the desired outcomes of the pupils and this requires effective and appropriate use of teaching skills.

\footnotetext{
* Corresponding Author: Yar Zar Chit

Lecturer, Department of Educational Psychology,

Sagaing University of Education, Myanmar

Email: yarzar02@gmail.com
}

In order to fulfill the above goal, the major requirement is to have an appropriate organizational climate for the teacher to work in, and give their best. According to Iyer (2002), "teaching needs three qualities: Knowledge is the first, communication skill is the second, and aptitude is the third" [1]. According to Kulandalvel and Rao (1968), teaching aptitude is one of the robust indicators of teacher efficiency [2]. An aptitude is not inborn; however, it is a combination of inborn capacities and developed abilities and skills. Bingham (1937) defined aptitude as "a condition symptomatic in his readiness to acquire proficiency, his potential ability and another in his readiness to development an interest in exercising his ability" [3].

Teaching aptitude may be defined as "a specific capacity or special ability, distinct from the general intellectual ability of an individual, indicative of his probable success in a particular field after receiving appropriate opportunity for learning or training" (Kaur, 2014) [4]. Therefore, teaching aptitude can be considered as the introduction determinant factor of effective teaching. A modern view of teaching aptitude includes professional activities in the school, such as co-operating in teams, building professional learning 
communities, participating in school development and evaluating and changing working conditions.

Various studies have proposed different criteria on how to assess teaching aptitude. However, in explaining teaching aptitude, there are important common factors that need to be considered. In this research, Vashistha's (1973) four dimensions of teaching aptitude were used [5]. They are teacher's enthusiasm, teacher's morale, teacher's efficacy and teacher's competence.

\subsection{Aim of the Study}

The main aim of this study is to assess teaching aptitude of 2016 intake teacher trainees during their attendance in Sagaing University of Education, Myanmar. This study more specifically addresses the following objectives:

(1)To examine the teacher trainees' teaching aptitude across the time intervals

(2)To compare the teacher trainees' teaching aptitude across the time intervals by gender

(3)To compare the teacher trainees' teaching aptitude across the time intervals by previous achievement

(4)To assess some factors influencing on the teacher trainees' teaching aptitude

\section{Material and Methods}

\subsection{Participants}

This study involved 263 teacher trainees (Male=112, Female=151) who enter Sagaing University of Education (SUOE) as first year BEd students in 2016 and they were assessed till 2019 by four different times. They were selected by using purposive sampling technique.

\subsection{Research Instrument}

There are four dimensions in Teaching Aptitude Test used in this research: teacher's enthusiasm, teacher's morale, teacher's efficacy and teacher's competence. The test items were adapted from Teaching Aptitude of Indian Competitive Exams of Chhattisgarh (TAICE). For content and face validity, six experts from Educational Psychology field were requested to do the editorial review of items. The pilot test was constructed with 30 items. It was administered to 60 first year BEd students from Sagaing University of Education on August 2016.

After item analysis procedure, a total of 25 items were selected to conduct the final test administration. Then, a factor analysis with varimax rotation was conducted to confirm that the test included four factors loading for four dimensions of teaching aptitude. Factor 1 (teacher's enthusiasm) was primarily loaded by ten items, factor 2 (teacher's competence) was loaded by seven items, factor 3 (teacher's morale) was loaded by four items, and factor 4 (teacher's efficacy) was loaded by four items. All of the test items were multiplechoice items with four alternative responses. Responses were scored 1 if answered correctly and 0 if answered incorrectly. The internal consistency of this instrument was 0.78 .

\subsection{Research Method}

Since it attempted to assess the teaching aptitude of teacher trainees, longitudinal research design and survey method were taken in this study.

\subsection{Procedure}

The data were collected at four different times. At first, the data were collected from the teacher trainees at the beginning of first year attendance in 2016 (Time 1). The second data set were collected after they completed first year course in 2017 (Time 2). Then the third data set were collected when they completed second year course in 2018 (Time 3). Finally, the fourth data set were collected after their third year course in 2019 (Time 4). In other words, it took three academic years to collect the four data sets. After collecting the required data, data analysis procedure was continued. Finally, to confirm the results, the interview protocols were done.

\section{Results and Discussion}

\subsection{Comparison of Trainees' Teaching Aptitude Across Time Intervals}

To compare the trainees' teaching aptitude across time intervals, descriptive analysis was firstly done. According to Table 1, teacher trainees' teaching aptitude increase across time intervals. However, to assess whether there were significant differences among the means of teaching aptitude, a repeated measures ANOVA, with Huynh-Feldt correlation, was conducted (see Table 2).

According to Table 2, the teacher trainees' teaching aptitude increase were significantly different, F (2.34, $613.73)=110.003, \mathrm{p}<0.001$, eta $^{2}=0.296$. Polynomial contrasts indicated, in support of this, there was a significant linear trend $(\mathrm{p}<0.001)$ and this finding was qualified by the significant quadratic trend, $(\mathrm{p}<0.001)$, reflecting the higher teaching aptitude for Time 2, 3 and 4 than Time 1 . To be clearer, a line graph showing teaching aptitude changes in Figure 1.

\subsection{Comparison of Trainees' Teaching Aptitude Across Time Intervals by Gender}

To compare the trainees' teaching aptitude across time intervals by gender, descriptive analysis was firstly done. According to Table 3, teacher trainees' teaching aptitude increase across time intervals by gender. 
Table 1. Descriptive Result of Participants' Teaching Aptitude across Time Intervals

\begin{tabular}{llllll}
\hline & $\mathrm{N}$ & Minimum & Maximum & Mean & Std. Deviation \\
\hline Time 1 & 263 & 6 & 19 & 14.24 & 2.362 \\
Time 2 & 263 & 6 & 22 & 14.68 & 2.408 \\
Time 3 & 263 & 6 & 22 & 16.06 & 2.730 \\
Time 4 & 263 & 10 & 23 & 17.60 & 2.498 \\
\hline
\end{tabular}

Table 2. Repeated Measures ANOVA Result of Mean Comparison Across Time Intervals

\begin{tabular}{llllllll} 
Source & & $\begin{array}{l}\text { Type III } \\
\text { Sum of } \\
\text { Squares }\end{array}$ & df & $\begin{array}{l}\text { Mean } \\
\text { Square }\end{array}$ & F & $p$ & $\begin{array}{l}\text { Partial Eta } \\
\text { Squared }\end{array}$ \\
\hline \multirow{3}{*}{ Time } & Huynh-Feldt & 1819.539 & 2.342 & 776.757 & 110.003 & .000 & .296 \\
& Linear & 1732.768 & 1 & 1732.768 & 228.250 & .000 & .466 \\
& Quadratic & 79.393 & 1 & 79.393 & 21.370 & .000 & .075 \\
& Cubic & 7.378 & 1 & 7.378 & 1.410 & .236 & .005 \\
\hline
\end{tabular}

Table 3. Descriptive Result of Participants' Teaching Aptitude by Gender

\begin{tabular}{|c|c|c|c|c|c|}
\hline Gender & & Time1 & Time2 & Time3 & Time4 \\
\hline & Mean & 13.69 & 14.41 & 16.23 & 18.26 \\
\hline \multirow[t]{3}{*}{ Male } & $\mathrm{N}$ & 112 & 112 & 112 & 112 \\
\hline & Std. Deviation & 2.156 & 1.906 & 2.980 & 2.680 \\
\hline & Mean & 14.64 & 14.89 & 15.93 & 17.13 \\
\hline \multirow[t]{2}{*}{ Female } & $\mathrm{N}$ & 151 & 151 & 151 & 151 \\
\hline & Std. Deviation & 2.431 & 2.718 & 2.530 & 2.865 \\
\hline
\end{tabular}

Table 4. Mixed ANOVA Result of Mean Comparison across Time Intervals by Gender

\begin{tabular}{llllll}
\hline Source & $\begin{array}{l}\text { Type III Sum of } \\
\text { Squares }\end{array}$ & df & Mean Square & F & $p$ \\
\hline Gender & .005 & 1 & .005 & .001 & .980 \\
Error & 2233.493 & 261 & 8.557 & & \\
Linear & 156.297 & 1 & 156.297 & 22.259 & .000 \\
\hline
\end{tabular}

However, to assess whether there were significant differences in gender and teaching aptitude, a mixed ANOVA, with Huynh-Feldt correlation, was conducted (see Table 4).

Table 4 indicated that there was no significant main effect of gender $\mathrm{F}(1,261)=0.001, \mathrm{p}>0.05$. Moreover, the linear trend was significant for the interaction between teaching aptitude and gender $(\mathrm{p}<0.001)$. To be clearer, a line graph showing teaching aptitude changes across time intervals by gender in Figure 2 .

\subsection{Comparison of Trainees' Teaching Aptitude Across Time Intervals by Previous Achievement}

In this section, previous achievement means their matriculation examination marks. The participants were classified into three groups based on their total marks in matriculation examination. Based on descriptive analyses of exam marks, students with scores above the $(+1)$ standard deviation from the sample mean were identified as the high group and students with scores below the $(-1)$ standard deviation were identified as the low group. And then, students with scores between (+1) and (-1) standard deviation were identified as the middle group.

To compare the trainees' teaching aptitude across time intervals by previous achievement, descriptive analysis was firstly done. According to Table 5, teacher trainees' teaching aptitude increase across time intervals by previous achievement. 
Table 5. Descriptive Result of Participants' Teaching Aptitude by Previous Achievement

\begin{tabular}{llllll}
\hline Group & & Time1 & Time2 & Time3 & Time4 \\
\hline \multirow{3}{*}{ High } & Mean & 14.48 & 14.66 & 16.16 & 17.07 \\
& $\mathrm{~N}$ & 44 & 44 & 44 & 44 \\
& Std. Deviation & 2.654 & 2.925 & 3.072 & 2.905 \\
\hline \multirow{3}{*}{ Middle } & Mean & 14.04 & 14.65 & 15.92 & 17.70 \\
& $\mathrm{~N}$ & 168 & 168 & 168 & 168 \\
& Std. Deviation & 2.354 & 2.367 & 2.726 & 2.341 \\
\hline \multirow{3}{*}{ Low } & Mean & 14.68 & 14.78 & 16.48 & 17.70 \\
& $\mathrm{~N}$ & 50 & 50 & 50 & 50 \\
& Std. Deviation & 2.084 & 2.083 & 2.426 & 2.621 \\
\hline
\end{tabular}

Table 6. Mixed ANOVA Result of Mean Comparison Across Time Intervals by Previous Achievement

\begin{tabular}{llllll}
\hline Source & $\begin{array}{l}\text { Type III Sum } \\
\text { of Squares }\end{array}$ & df & Mean Square & F & $\mathrm{p}$ \\
\hline Intercept & 182281.099 & 1 & 182281.099 & 21384.836 & .000 \\
Group & 17.297 & 2 & 8.649 & 1.015 & .364 \\
Error & 2216.201 & 260 & 8.524 & & \\
\hline
\end{tabular}

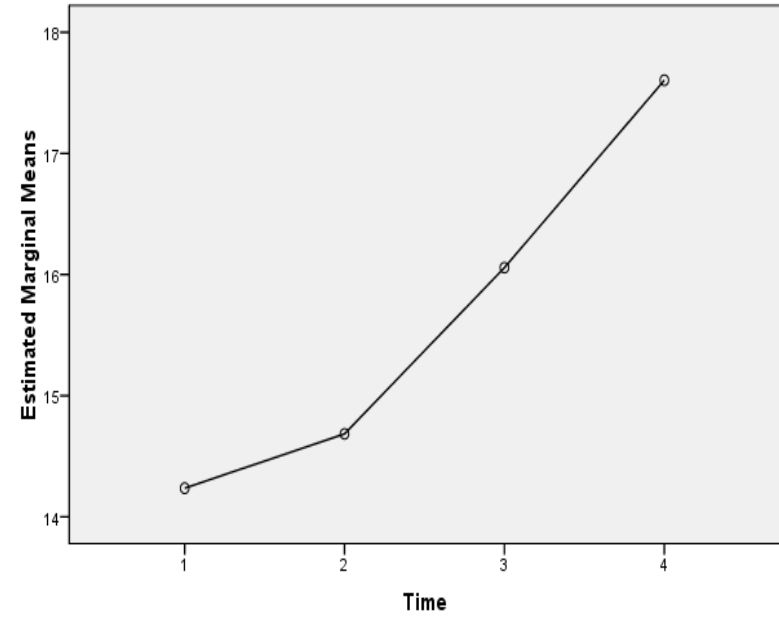

Figure 1. Comparison for Mean Values of Teaching Aptitude

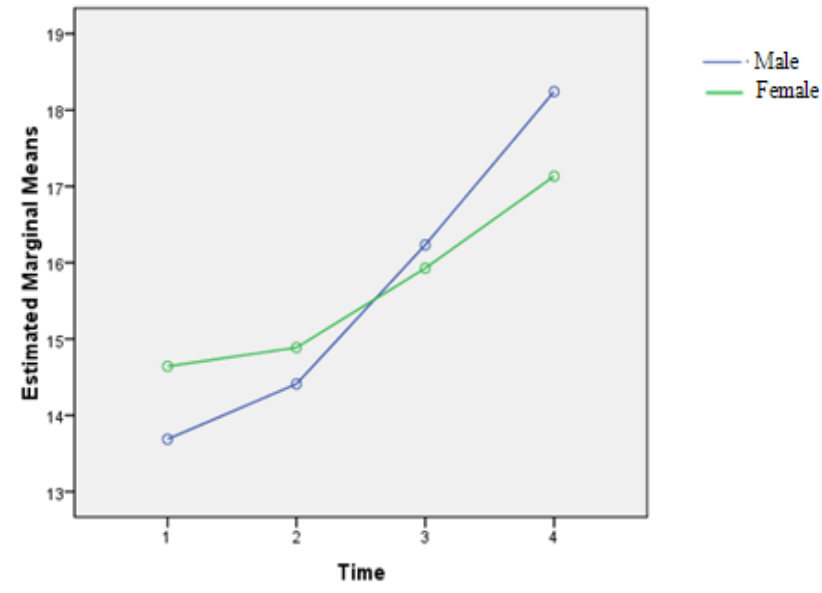

Figure 2. Comparison for Mean Values of Teaching Aptitude by Gender

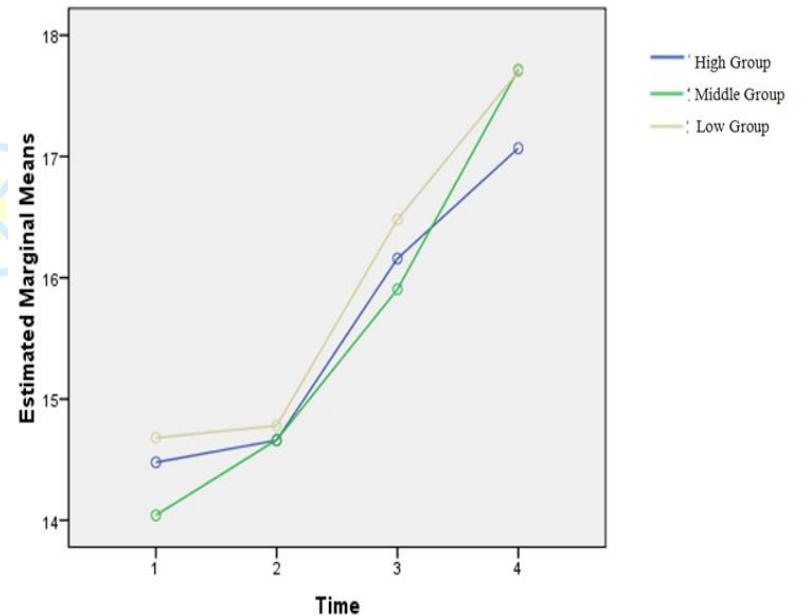

Figure 3. Comparison for Mean Values of Teaching Aptitude by Previous Achievement

However, to assess whether there were significant differences in previous achievement and teaching aptitude, a mixed ANOVA, with Huynh-Feldt correlation, was conducted (see Table 6).

Table 6 indicated that there was no significant main effect of previous achievement $\mathrm{F}(2,260)=1.015$, p $\& \mathrm{gt} ; 0.05$. To be clearer, a line graph showing teaching aptitude changes across time intervals by previous achievement in Figure 3.

\subsection{Interview Results}

With respect to the improvement of teacher trainees' teaching aptitude, six trainees were interviewed about their training experiences in Sagaing University of Education. During the three years, they performed many teaching learning activities in the classes and 
many practical activities out of the classes for all subjects. For example, peer-group teaching, presentation, group discussion, making teaching aids, observation and recording a person, constructing a systematic test, bloc teaching, taking part the impromptu talks, etc.

Moreover, they said that their teachers' instruction was very interested and they used many teaching aids and many attractive activities. They responded that the reason was because of EfECT (English for Education College Teachers) training of British Council. Therefore, they seemed that their teaching aptitudes were improved.

\section{Conclusions}

The main aim of this study was to assess teaching aptitude of 2016 intake teacher trainees during their attendance in Sagaing University of Education. To achieve this aim, four specific objectives were taken.

According to the research findings, teacher trainees' teaching aptitudes were significantly improved during three academic years. This may be due to the effective teaching learning activities of teacher trainers in Sagaing University of Education.

Again, in gender comparison, female trainees were higher than males in teaching aptitude at the beginning of the BEd program. In the last time testing, male trainees were higher than females. However, it was found that there was no significant main effect of gender. It may be a good result for Sagaing University of Education because it shows that this university could train its trainees without any difference by gender. In other words, the trainings of SUOE give equal chance for both male and female trainees.

Moreover, according to comparison of trainee groups by previous achievement, there was also no significant main effect of previous achievement. This is also a good result because it shows that this university could train its trainees without any difference by previous achievement. In other words, the trainings of SUOE promote the teaching aptitude of not only the trainees who got high marks in matriculation examination but also ones who got usual marks. The level of achievement in matriculation examination has no apparent influence in predicting teaching aptitude.

Therefore, based on the literature review and the research findings, the following suggestions would be given for the teacher trainings.

(i) Teacher trainings should use not only lecture methods but also innovative and active teaching strategies to promote trainees' teaching aptitude.

(ii) Teacher trainers in a teacher education program should be occasionally given opportunities to improve their qualifications by giving upgrading programs. (iii) Introduction of the teaching aptitude test as a part of the entrance examination for teacher education program may help to improve the efficiency of the program. Therefore, it should be included in trainee selection procedure of teacher trainings.

(iv) Uphill struggle should be made for inculcate the liability and favorable teaching aptitude in the teacher's nature while their training as teachers.

(v) The duration of their teaching practice need to be increased to enhance their teaching aptitude.

To sum up, this study highlighted the effectiveness of training procedures of Sagaing University of Education. On the other ways, this university may be said as a sample of teacher trainings in this paper and so, the effectiveness of this university may be a sign of all teacher trainings. Therefore, this paper hoped that the teacher trainers and the educators of the teacher training programs will get some ideas to promote the teaching aptitude of their trainees.

\section{Acknowledgements}

The author would like to express the heartfelt indebtedness to BEd students who continuing participated in this research for three years for their willingness to openly share their time and experiences. Without their inspiring presence, the author would not have been competent enough to accomplish the research.

\section{References}

[1]. Iyer, V. M. (2002). Making A Good Teacher. The Hindu (Online edition of India's National Newspaper), Tuesday, September 3, 2002.

[2]. Kulandalvel, K. \& Rao, T. R. S. (1968). Qualities of Good Teachers and Good Students (A Study of Student Rating). Coimbotore: R. K. Mission Vidhyalaya.

[3]. Bingham, W. V. D. (1937). Aptitudes and Aptitude Testing. New York: Harper \& Brothers.

[4]. Kaur, M. (2014). A Comparative Study of Teaching Aptitude of BEd (General) Pupil Teachers of Kurukshetra District in Relation to Their Gender, Location, Stream and Professional Experience Education. Indian Journal of Research, 3(8), 212-235.

[5]. Vashishta, K. K. (1973). A Study of Predictive Efficiency of Admission Criteria for B.Ed. Students. Journal of Education and Psychology, 3(7), 14-27. 